\title{
ARTICULAÇÕES ENTRE EDUCAÇÃO INTERCULTURAL E PRÁTICAS DE INTERNACIONALIZAÇÃO ENTRE O MÉXICO E O BRASIL ${ }^{1}$
}

\author{
ARTICULACIONES ENTRE EDUCACIÓN INTERCULTURAL Y PRÁCTICAS DE \\ INTERNACIONALIZACIÓN ENTRE MÉXICO Y BRASIL
}

\author{
ARTICULATIONS BETWEEN INTERCULTURAL EDUCATION AND \\ INTERNATIONALIZATION PRACTICES BETWEEN MEXICO AND BRAZIL
}

\author{
Antonio Carrillo AVELAR ${ }^{2}$ \\ Andrea Olmos $\mathrm{ROA}^{3}$ \\ Iracema Campos CUSATI
}

RESUMO: Como parte do processo de internacionalização, apresentamos uma proposta de formação desenvolvida com estudantes indígenas de graduação vinculados ao Núcleo Takinahaky de Formação Superior de Professores Indígenas da Universidade Federal de Goiás - UFG, Brasil, por meio de um processo de documentação narrativa de experiências. Nosso objetivo foi compreender, vis-a-vis relatos de experiências de estudantes indígenas, as teorias que fundamentam a abordagem didática de um projeto de articulação institucional como prática de internacionalização binacional. Começamos explicitando os desafios e as possibilidades de mudanças na prática educativa, para tentar possibilitar o diálogo do conhecimento e de cosmovisões dos povos indígenas em relação às demandas contemporâneas da vida intercultural. Da mesma forma, contextualizamos a formação de professores em contextos interculturais, destacando crenças, compromissos sociais e culturais, reflexões e avaliações que os professores expressaram sobre a experiência acadêmica em que participaram e, finalmente, considerações finais que delineiam algumas derivações práticas sobre essa proposta de formação e inovação.

\footnotetext{
${ }^{1}$ O presente trabalho foi realizado com o apoio da UPE, entidade do Governo do Estado de Pernambuco voltada para o fomento ao Ensino, a Pesquisa e a Extensão.

${ }^{2}$ Universidade Nacional Autónoma do México (UNAM), Cidade do México - México. Professor e investigador do Programa de Pós-graduação da Universidade Pedagógica Nacional e do Programa de Pós-graduação em Pedagogia da UNAM no México. Doutor em Ciências Antropológicas pela Universidade Autônoma Metropolitana - México. Professor convidado do Programa de Pós-graduação Interdisciplinar em Direitos Humanos da Universidade Federal de Goiás/UFG - Brasil. ORCID: <https://orcid.org/0000-0002-5654-0650>. Correo: antoniocarrillobr@hotmail.com

${ }^{3}$ Universidade Nacional Autónoma do México (UNAM), Cidade do México - México. Professora e pesquisadora do Programa de Pós-graduação de Psicologia (FES Zaragoza) e do Programa de Pós-graduação em Pedagogia da Universidade Nacional Autônoma do México (FES Aragón). Doutora em Comunicação, Cultura e Educação pela Faculdade de Estudos Sociais da Universidade de Salamanca - Espanha. ORDIC: <https://orcid.org/0000-00017422-1701>.Correo: andreaolmos@gmail.com

${ }^{4}$ Universidade de Pernambuco (UPE), Petrolina - PE - Brasil. Professora Permanente e Orientadora do Programa de Pós-graduação em Formação de Professores e Práticas Interdisciplinares da UPE. Doutora em Educação pela Universidade de São Paulo (FEUSP) - Brasil. ORCID: <https://orcid.org/0000-0002-4812-8412>. E-mail: iracema.cusati@upe.br
} 
PALAVRAS-CHAVE: Formação de professores indígenas. Tequio (trabalho coletivo voluntário $^{5}$ ). Práticas de internacionalização.

RESUMEN: En el marco de los procesos de internalización, presentamos una propuesta académica realizada con estudiantes indígenas de posgrado, realizado en el Núcleo Takinahaky de Formación Superior de Profesores Indígenas de la Universidad Federal de Goiás, Brasil, a través de un proceso de documentación narrativa de experiencias. Nuestra finalidad era comprender a través de relatos de experiencia de estudiantes indígenas, las teorías que subyacen sobre el planteamiento didáctico de un proyecto de vinculación institucional, como práctica de internacionalización binacional. Iniciamos con los desafíos y posibilidades para cambios en la práctica educativa al intentar posibilitar el diálogo de los saberes y cosmovisiones de los pueblos indígenas en cuanto a las demandas contemporáneas de vida intercultural. Así mismo contextualizamos la formación docente en contextos de interculturalidad, destacando las creencias, compromisos sociales y culturales, reflexiones y valoraciones que los docentes expresaron sobre la experiencia académica en que participaron y finalmente consideraciones finales que esbozan algunas derivaciones prácticas sobre esta propuesta formativa y de innovación.

PALABRAS CLAVE: Formación de docentes indígenas. Tequio ${ }^{6}$ académico. Prácticas de internacionalización.

ABSTRACT: As part of the internationalization process, we present a proposal of training developed with indigenous undergraduate students linked to the Takinahaky nucleus of higher education of indigenous teachers of the Universidade Federal de Goiás- UFG, Brazil, through a process of narrative documentation of experiences. Our goal was to understand, vis-a-vis reports of experiences of indigenous students, the theories that support the didactic approach of a project of institutional articulation as a practice of binational internationalization. We begin by explaining the challenges and possibilities of changes in the educative practice, to try to enable the dialogue of knowledge and cosmovisions of indigenous peoples in relation to the contemporary demands of intercultural life. Similarly, we contextualize the formation of teachers in intercultural contexts, highlighting beliefs, social and cultural commitments, reflections and assessments that teachers expressed about the academic experience in which they participated and, Finally, concluding considerations outlining some practical derivations on this proposal for training and innovation.

KEYWORDS: Formation of indigenous teachers. Tequio (voluntary collective work). Internationalization practices.

${ }^{5}$ No México, é conhecido como tequio o trabalho individual ou trabalho coletivo, não remunerado, que cada cidadão fornece à sua comunidade. É um costume indígena e usam isso com nuances diferentes embora o envolvimento seja contínuo e enraizado na cultura de várias áreas deste país.

${ }^{6}$ En México se conoce como tequio a la faena o trabajo colectivo no remunerado que todo vecino de un pueblo debe a su comunidad. Es un uso y costumbre indígena que con diversos matices y fuerza continúa arraigado en varias zonas de este país. 


\section{Introdução}

As universidades públicas na América Latina, no contexto da globalização, estão sujeitas a forças e tensões, que derivam em políticas públicas, pela necessidade de gerar propostas para enfrentar os desafios atuais de formação, buscando consolidar ações que atendam às demandas educacionais do mundo globalizado. Neste cenário, uma das mais complexas estratégias educacionais e políticas, com as quais as instituições de ensino superior têm de enfrentar os novos desafios no contexto da globalização, é a internacionalização. Em decorrência disso, como aponta Didriksson (2015), existe atualmente uma grande política de interdependência econômica, social e cultural, facilitada recentemente pela mídia de informação e comunicação, como ressaltam Reimers e Chung (2016, p. 13):

O campo da educação não ficou imune a essa turbulência, pois houve mudanças repentinas dentro e fora dos sistemas educacionais: a chegada da aprendizagem on-line, personalizada e internacional, por exemplo, parece ter tornado permeáveis os limites dos edifícios escolares [...] (Tradução nossa)

Hoje é comum ver a colaboração acadêmica entre países que intentam reforçar mutuamente em um cenário internacional em que se busca a sustentação e o aprimoramento de alianças estratégicas neste caso com Universidades.

El sistema educativo de Singapur aprende constantemente de otros: envía a sus profesionales a otros países a obtener posgrados para que puedan aportar lo que aprendieron, o formar redes con escuelas de otros países para intercambiar prácticas e ideas (MALONE, 2016, p. 34).

Atualmente, as universidades da América Latina são parte das instituições de elite do Ensino Superior no mundo, daí a importância de retomar o papel de protagonismo nesta cultura globalizante, a abertura das fronteiras em educação, as oportunidades de desenvolvimento bem como o fortalecimento de seus respectivos programas acadêmicos e de seus alunos ao favorecer o compartilhamento de experiências em suas funções substantivas e apoiar com infraestrutura que permita o desenvolvimento de atividades formativas.

Como sabemos, a educação pública na América Latina, apesar de ter conseguido avanços importantes nas últimas décadas em diferentes níveis e modalidades, os resultados obtidos não atenderam plenamente às expectativas de qualidade que a sociedade colocou na educação. Ainda persistem grandes problemas nas instituições de ensino: a questão de como elas têm práticas de convivência humana não resolvidas que são refletidas na estagnação dos direitos humanos e no atraso educacional a uma crescente demanda por serviços; a eficiência terminal baixa expondo uma mostra notável de disparidades nos vários níveis de ensino; 
formalismo e didatismo na aplicação de programas de estudo; pouco desenvolvimento de pesquisa; lacuna entre processos educacionais e processos produtivos, entre outros (SUÁREZ; HILLERT; OUVINÃ; RIGAL, 2016).

Tudo isso requer respostas de nossas universidades alinhada às condições sociais vigentes e cada vez mais complexas, especialmente para aqueles que acreditam que a escola continua a ser um fator de importância estratégica para o desenvolvimento moral e intelectual de uma sociedade que aspira ter uma educação para a altura que nossos tempos exigem.

Nesse sentido, as práticas de internacionalização nas universidades latino-americanas de hoje têm sido consideradas como um importante elemento no desenvolvimento das políticas educacionais atuais, pois surgem como um recurso que busca, por meio de práticas de articulação e mobilidade, atender aos sujeitos envolvidos oriundos de outros lugares e inserilos em diferentes formas de produção de conhecimento a partir desse cenário enriquecedor entre instituições e práticas de formação acadêmica.

O interessante é pensar sobre como aproveitar as atividades oferecidas neste espaço universitário quase totalmente globalizado, onde proliferam reuniões, encontros e oportunidades de intercâmbio e também considerar os questionamentos sobre a existência de várias formas de ver e interpretar o mundo nesta gigantesca rede comunicação, em que, muitos dizem, todos nós devemos participar. Consideramos que é importante que nestes programas de intercâmbio sejam considerados aqueles que socioculturalmente apresentem diferentes formas de participantes, que se caracterizem interculturalmente por facilitar o falar, o ouvir e o discutir em diferentes línguas que também expressam as várias formas de pensar, sentir, agir... especialmente grupos culturais que foram invisíveis, silenciados, marginalizados, naquele mundo interconectado que se caracteriza, em geral, por privilegiar certas vozes, as ocidentais, para que, de fato, se estabeleça um verdadeiro diálogo. Vale destacar também que todas as formas de escrever e ler, falar e escutar, precisam alcançar o que reconhecemos como sendo parte de diferentes culturas e visões que podem compartilhar, numa tentativa de traduzir, e que apresentem possibilidades de apropriação de outros saberes alcançando uma visão mais ampla.

Felizmente, existem várias propostas que compactuam com essa proposta de construção, revitalização e formação de professores em nosso cenário latino-americano, tentando incentivar as referidas práticas internacionalização, em específico, estudos de pós-graduação para estudantes indígenas, com a intenção de integrar diversos projetos de intervenção e pesquisa nos níveis de especialização de mestrado e doutorado, com o objetivo de promover maior intercâmbio, participação e capacitação dos atores envolvidos na tarefa educativa de alunos, professores e gestores. A possibilidade de alcançar este objetivo depende da construção de 
espaços acadêmicos mais realísticos e situados que considerem essa pluralidade de vozes e ajudem a analisar criticamente o significado e o alcance da tarefa educacional.

\section{A mobilidade dos estudantes indígenas: um Programa educativo intercultural}

É importante questionar algumas práticas em programas de internacionalização que procuram legitimar uma forma de ver e praticar os processos de mobilidade, padronizar currículos, viagens, línguas e experiências culturais, numa espécie de colonialismo cultural que, sob a alegação de valorizar a interculturalidade, na realidade o discurso e as ações parecem não condizer.

Estamos interessados num programa que promova e valorize a interculturalidade e encoraje o diálogo e a convivência, para desenvolver o sentimento de igualdade como précondição para o conhecimento e o respeito pelas diferenças culturais. Deste ponto de vista, podemos dizer que o sistema educacional tem o objetivo fundamental de que todos os alunos possam alcançar uma competência cultural sólida, ou seja, desenvolver atitudes e habilidades para viver em uma sociedade multicultural e multilíngue, enfatizando o estabelecimento de um diálogo com o eixo de trabalho intercultural.

Nos dias atuais parece não haver dúvida de que uma formação acadêmica adequada ao nível de pós-graduação para os povos nativos, deve ser articulada com uma série de experiências que têm grande significado individual e social. Assim, as chamadas práticas de internacionalização que estão atualmente em voga nas diferentes instituições levantam em essência repensar a tarefa educacional como uma tarefa que busca substituir o modelo tradicional de ensino na escola nas universidades (ZAMBRANA, 2014).

Se nos concentrarmos nas práticas acadêmicas de pós-graduação em educação indígena, fica ainda mais evidente a importância da mobilidade de professores e alunos como fator de atualização e inovação das práticas educacionais tradicionais. Em uma sociedade moderna como a nossa, estudos de pós-graduação em educação exigem a criação de novas competências para o trabalho intelectual. Nessa perspectiva, os alunos do mestrado em educação que também são professores em serviço tornam-se, consequentemente, uma importante fonte de inovação e atualização dos níveis educacionais em que estão imersos.

Ou seja, as aulas na pós-graduação em geral e em particular para os povos indígenas podem se tornar não apenas espaços onde diferentes conteúdos disciplinares são aprendidos, mas é bem verdade que esses espaços acadêmicos também se tornam locais onde diferentes habilidades são desenvolvidas, paralelamente. Ao adquirir o conteúdo que é exigido em 
determinado grau acadêmico, para os quais os processos de inovação que necessitam de nossos tempos, como a inclusão de novas tecnologias de informação e comunicação em conjunto com a internacionalização hoje, também são obrigatoriedades assumidas pelas instituições de ensino que formam em níveis de pós-graduação, mas sem esquecer:

Esta armonización entre lo viejo y lo nuevo revela cuan adaptables e ingeniosos pueden ser los educadores para explorar nuevas tecnologías con sus estudiantes. Más allá de fomentar la tecnología, cuestionarla o proteger de ella a los estudiantes, existe una reconocida tierra fértil de cambio educativo que armoniza lo mejor de las prácticas tradicionales con o prometedor y el potencial de la tecnología (SHIRLEY, 2016, p. 48).

Embora as vantagens formativas de vinculação como, por exemplo, as práticas de internacionalização no desenvolvimento educacional de pós-graduados, sua implementação na formação tradicional ainda não é muito evidente. Um dos elementos mais preocupantes é que os estudos de pós-graduação na área das Ciências Sociais e Humanas devem estar na vanguarda dos grandes avanços da didática e da tecnologia; no entanto, na prática, isso não acontece. As explicações para esse problema são múltiplas, mas a mais premiada nesse campo talvez seja a que indica que para esse tipo de acadêmico não é exigido esses processos atuais, como a mobilidade internacional e o uso de tecnologias.

O Programa de Pós-Graduação e o Intercâmbio de Relações Acadêmicas em Educação da Universidade Nacional Autônoma do México, a FES Aragón, que se desenvolve entre Brasil e México, pretende ser um encontro acadêmico focado no fortalecimento da formação teórica metodológica de alunos no ensino superior, onde recupera e valoriza a própria experiência institucional, cuja estrutura formativa reconhece o contexto de uma educação localizada e centrada na defesa dos direitos humanos e culturais dos povos indígenas. De tal forma que os estudantes indígenas estejam conscientes e reflitam sobre os aspectos de sua formação que precisam ser repensados, reforçados, modificados ou consolidados.

Talvez devido à falta de práticas de internacionalização de pós-graduação para os povos indígenas, requeira uma mudança de perspectiva acadêmica e reorientação didática dos programas de mestrado. Do nosso ponto de vista, qualquer intervenção educacional prima por um processo de imaginação criativa que põe em jogo os vários recursos atuais que o programa possui e, a partir deste, faz novas abordagens pedagógicas. Portanto, é necessário propor uma intervenção didática que tenda a superar os problemas acima mencionados.

Mejorar la docencia especialmente en tiempos de cambio acelerado no significa sólo perfeccionarse en hacer lo mismo, quiere decir que la docencia también debe hacerse más innovadora. El mejoramiento también se ha 
convertido en una actividad de responsabilidad creciente en diversos países (STOLI, 2016, p. 63).

Os principais objetivos deste trabalho são socializar e compartilhar, para que, através do diálogo e de intercâmbio com colegas e estudiosos ou interessados no assunto, seja possível enriquecer essa proposta de formação, a fim de ter melhores elementos acadêmicos que nos ajudem a desenvolver um curso de pós-graduação relevante para os povos indígenas, baseado nas circunstâncias acadêmico-administrativas que temos que conviver. Neste contexto, trabalhando com os estudantes, as diversidades culturais podem ser incentivadas ou promovidas práticas de troca, de intercâmbio, para que os alunos possam compreender de modo localizado, a importância de defender os direitos humanos e culturais, de conhecer a realidade sociocultural e a realidade educacional em particular de seu ambiente, para fazer previsões e projeções acadêmicas, e assim antecipar problemas que vão contra seus direitos.

Estudiosos e interessados nas ciências sociais e educação, em particular, devemos nos comprometer com essa realidade permitindo ambientes acadêmicos que promovam a aprendizagem dos estudantes e uma compreensão do contexto localizado socioculturalmente, permitindo-lhes desenvolver habilidades sociais para avaliar e reconhecer a riqueza criativa que o ser humano tem como entidade social e que, por sua vez, poderá fortalecê-los pedagogicamente. Para alcançar o acima exposto, consideramos importante que os participantes, neste espaço formativo, desenvolvam as habilidades necessárias de raciocínio e criatividade para colocar em prática uma tarefa formal de acordo com nossos tempos.

A perspectiva fundante desta proposta é baseada na abordagem que considera a gênese da aprendizagem e da formação dos alunos de origem sociocultural (OLMOS; CARRILLO, 2009), e também num cenário educacional e cultural projetado, onde participantes inseridos apropriam-se dos pontos de vista do grupo, de suas atividades, suas maneiras de pensar, de agir e jogar num papel ativo por parte dos atores, buscando resignificá-lo e interpretá-lo para construir o conhecimento de forma contínua, e atrelado as práticas de internacionalização.

Os princípios nos quais a filosofia da internacionalização se baseia são os seguintes:

$\checkmark$ O processo de formação de estudantes indígenas no nível de pós-graduação deve ir além da experiência e informações locais fornecidas pelas universidades.

$\checkmark$ As representações existentes sobre a formação em e para povos indígenas no contexto das mudanças educacionais demandadas por uma sociedade do conhecimento, como a que vivemos hoje, devem ser repensadas ou consolidadas também nesses termos. 
$\checkmark \quad$ A atitude de compromisso e trabalho de reflexão constante é considerada a base de uma educação relevante focada em processos de internacionalização.

$\checkmark \mathrm{O}$ refinamento acadêmico existe na medida em que as estratégias realistas e contextualizadas de internacionalização, que acompanham a experiência, são valorizadas.

$\checkmark$ Devemos ter em mente que existem processos nas práticas de aprendizagem, por isso o programa é construído privilegiando três momentos de aprendizagem, o contexto de sua experiência profissional, analítica e integração que ocorre dentro da universidade e a promoção de experiências acadêmicas que permitem que você veja de outro lugar o que eles estão produzindo.

$\checkmark$ A constante reflexão sobre a diversidade cultural centrada na internacionalização, nos direitos humanos e na construção de estratégias situadas de aprendizagem é considerada a base do bom ensino.

$\checkmark$ Aprendizagem como uma prática social, em um sentido amplo que está associada à filosofia contextual e acadêmica, onde os sujeitos são autônomos e praticam sua própria posição acadêmica.

Para uma melhor compreensão do programa e de suas práticas de internacionalização, será apresentado o pano de fundo deste trabalho entre as instituições de Ensino Superior no Brasil e no México.

\section{Intercâmbio acadêmico: precedentes entre México e Brasil}

O pano de fundo deste trabalho entre instituições de Ensino Superior no Brasil e no México remonta a 2004, quando três professores de universidades brasileiras realizaram estadias de pesquisa no México. Posteriormente, em julho de 2005, foi realizado um colóquio interno para um professor de pós-graduação e seus alunos que pesquisavam no campo da interculturalidade, denominado "Experiências de pesquisa e práticas institucionais", organizado pelo Museu Antropológico do Universidade Federal de Goiás. Nos anos seguintes, eventos acadêmicos semelhantes foram organizados com mais membros acadêmicos do UPN, UNAM, UABJO e ENBIO. Tendo em vista o sucesso desses eventos, considerou-se necessário organizar uma conferência em nível internacional sobre Formadores de Educação Intercultural, que também convocariam outras universidades da América Latina, e que favorece acordos significativos que permitem consolidar o campo da diversidade cultural em contextos de direitos humanos.

Atualmente, a experiência de vinculação entre as duas universidades foi consolidada com a presença de um professor visitante do México e com a curta permanência em pesquisa 
de dois professores da Universidade Federal de Goiás em universidades mexicanas e, posteriormente, com a presença de um pesquisador da rede FEIAL da Universidade Autônoma Benito Juárez de Oaxaca. Atualmente, os integrantes deste projeto estão participando da elaboração da memória do evento e na elaboração de diversos livros eletrônicos. Tudo isso no contexto dos pesquisadores mexicanos que também estão apoiando a documentação dessa experiência acadêmica.

A Faculdade de Estudos Superiores Aragón - ME desenvolveu em 2012 um projeto educacional junto a Secretaria de Pós-Graduação no contexto do Programa de Pós-Graduação em Pedagogia da UNAM. Com isto, iniciou um processo de mudança na cultura acadêmica no contexto de reestruturação curricular que abordava, por meio de disposições que marcam o CONACYT - Organismo avaliador - que reclama pela organização de um corpo docente segundo critérios organizacionais estabelecidos, a criação de Linhas de Gestão e Aplicação de Conhecimento (LGAC). Não foi uma dinâmica simples. Envolveu uma tutoria horizontal, na qual um grupo de professores, mestres e doutores analisaram e reorientaram, coletivamente, projetos e avanços da pesquisa e intervenção dos alunos que se formaram sem distanciar dos princípios da Aprendizagem Baseada em Problemas (BARELL, 1999) ${ }^{7}$. É reiterado que foram ações que envolveram uma mobilização complexa, um desafio para todos participantes.

Assim, tendo em conta o número de professores do Programa de Pós-Graduação da FES-Aragão, foram criadas oito Linhas de Geração e Aplicação de Conhecimento (LGAC) ${ }^{8}$. Esta ação acadêmica foi considerada como uma proposta pedagógica inovadora de acordo com a dinâmica de trabalho que foi levantada dentro de suas políticas públicas. A iniciativa surgiu como uma proposta de um grupo de professores, vários deles professores e pesquisadores de outras universidades e instituições de ensino superior, que se propuseram a fazer um trabalho conjunto com seus alunos, gerando questões coletivas de pesquisa que fariam sentido para o

\footnotetext{
${ }^{7}$ Aprendizagem Baseada em Problemas (ABP) é uma proposta metodológica que está sendo trabalhada atualmente em instituições de ensino superior. Diferentemente de como a abordagem do problema é trabalhada em cursos tradicionais de pesquisa onde o início e o fim da atividade são centrados no orientador ou no professor responsável pela atividade, no ABP, o aluno como membro de uma equipe de trabalho, e os professores responsáveis pela atividade, adquirem o papel máximo na identificação de suas necessidades de aprendizagem e buscam diferentes estratégias para alcançar o conhecimento e responder a um problema que, por sua vez, gera novas necessidades de aprendizagem.

${ }^{8}$ Os oito LGAC, do Programa de Pedagogia da FES de Aragão foram assim definidas: 1. Ensino Emergente e Ensino Alternativo na Educação, 2. Docência e Comunicação, 3. Gestão Acadêmica e Políticas de Gestão para a Educação, 4. Educação e Educação para a Diversidade Cultural, 5. Cidadania e Valores; 6. Educação e Diversidade Cultural: Gestão para o conhecimento sociocultural e linguístico, 7. Educação e Diversidade Cultural, Desenvolvimento Educacional e Inclusão, 8. Construção de Conhecimento Pedagógico, Formação e PósGraduação.
} 
trabalho de cada LGAC no contexto, como já mencionado, da abordagem acadêmica denominada Aprendizagem Baseada em Problemas.

Promover uma tutoria horizontal significa que os professores e os alunos se propõem a construir um projeto de pesquisa conjunto, que se tornou um excelente pretexto e texto, para executar uma tarefa de transformação da cultura acadêmica instituída, ou seja, foi considerado importante para organizar uma série de simpósios internamente programados, por semestre, que permitiriam o acompanhamento do processo de formação, a partir de uma equipe de professores organizada para realizar este trabalho. Em outras palavras, para promover este estilo de trabalho acadêmico em sala de aula, e dentro das dinâmicas institucionais do Programa de PósGraduação em Educação, foram exigidos dos representantes de cada LGAC, responsáveis pela gestão do conhecimento, que tivessem informações importantes sobre o processo estilo de treinamento $(\mathrm{ABP})$, de tal forma que os produtos acadêmicos dos alunos foram construídos a partir de abordagens metodológicas estabelecidas em reuniões anteriores e, assim, evitou a dispersão durante as avaliações de seus produtos de trabalho e, inclusive permitiu a reflexão dos envolvidos sobre o escopo e as limitações vivenciadas por aqueles que se propuseram a diariamente interagir coletivamente. No mesmo sentido, os princípios da pesquisa-ação participativa foram instalados, mais especificamente no LGAC: Educação e Diversidade Cultural: Gestão para o conhecimento sociocultural e linguístico. Neste processo foi considerado prudente elaborar um registo e controle da atividade acadêmica que foi pensada para colocar em prática, porque essa ação permitia a avaliação e coletivamente a reflexão sobre a reavaliação do significado que deve ter cada LGAC e suas perspectivas do trabalho acadêmico.

Outra linha que integra o Programa de Pós-Graduação em Pedagogia da FES Aragón, dentre as que já foram mencionadas, aproveitou a presença dos estudantes indígenas do Estado de Oaxaca que cursavam a pós-graduação na FES Aragón e considerou importante aproveitar suas práticas culturais ancestrais como o tequio $^{9}$ para vinculá-las à modalidade de trabalho denominada: Aprendizagem Baseada em Problemas (ABP).

Os estudantes indígenas são estudantes bolsistas do CONACYT e suas ocupações limitam-se apenas à realização de suas pesquisas. Nessa proposta, vários professores de diferentes formações disciplinares, trajetórias profissionais e experiências se encontraram, a fim

${ }^{9} \mathrm{O}$ tequio é um trabalho coletivo, livre e moralmente obrigatório; que todos os cidadãos devem realizar trabalhos voluntários para o benefício da comunidade. 
de contribuir para a solução dos principais problemas que coexistem nas salas de aula interculturais e bilíngues das escolas dos povos indígenas originários do Estado de Oaxaca ${ }^{10}$.

O tequio acadêmico articulado a ABP no contexto de um LGAC, foi considerado uma prática acadêmica relevante e conjuntural, pois rompe com a prática instituída de ter programas de tutoria individuais de professores que têm concepções muito particulares de ensino e que muitas vezes veem seus alunos como uma entidade isolada, à margem de um projeto acadêmico coeso e consensual.

\section{Estrutura didática da experiência}

A presente proposta parte de uma noção ampla de flexibilidade curricular (CASTAÑEDA, 2001), que a considera como um processo coletivo e individual de criação e recriação das formas de reorganização, percepção e interpretação do currículo, ou seja, como um processo de comunicação e interação entre diferentes espaços curriculares ou seminários. A flexibilidade é vista na organização horizontal e vertical, na elaboração de produtos acadêmicos e na maneira pela qual eles são concebidos, seus usos práticos, suas ligações com a realidade, originalidade, isto é, qualquer coisa que mostra sinais de uma gestão acadêmica adequada.

Reconhecer que os programas de mestrado têm a tarefa principal de produzir e criar conhecimento significa aceitar a diversidade acadêmica, ao contrário de outros currículos que são mais rígidos em suas práticas. Espera-se também que a vinculação e a internacionalização proporcionem aos alunos experiências socioculturais e educacionais extraclasse concretas que complementem e consolidem os processos de formação crítica e o fortalecimento de seus projetos de pesquisa, de modo que permitam aos alunos de pós-graduação relacioná-los com o sentido acadêmico e autônomo que rege a linha de geração e aplicação do conhecimento onde estão inseridos, com vistas a favorecer e enriquecer uma percepção integral.

A seguir, são enumerados os objetivos da experiência de internacionalização:

$\checkmark$ Propor elementos acadêmicos concretos para envolver estudantes de pósgraduação e professores em uma experiência alternativa de treinamento entre duas instituições.

${ }^{10}$ Los profesores que están participando son: Los profesores integrantes de esta LGAC, eran 4: Un académico indígena, un antropólogo, un pedagogo y un lingüista. 
Identificar problemas acadêmicos muito específicos que possam ser articulados ao projeto de pesquisa.

$\checkmark$ Estabelecer diretrizes de trabalho e implementação de internacionalização que contribuam para favorecer uma estratégia de articulação dentro das linhas acadêmicas que compõem a proposta de trabalho.

$\checkmark$ Potencializar as condições acadêmicas e materiais, existentes no programa de pós-graduação, para possibilitar um maior processo de internacionalização.

$\checkmark$ Explorar elementos específicos de logística dentro das instituições para promover práticas de internacionalização.

Portanto, após os preâmbulos, o texto aqui apresentado composto por três seções, traz na sequência, com base na estrutura contextual do seminário de investigação, os fundamentos para trabalhar a investigação em duas direções, a primeira ligada à solução de um grupo que usa sua experiência como indígenas no tequio e outro por meio de um treinamento focado em ABP. A segunda seção apresenta a versão que visa analisar a história e as abordagens teóricas da disciplina e seus vínculos às práticas de internacionalização, como a promoção de uma vigilância epistêmica aos objetos de estudo dos estudantes. A terceira seção enfoca o conhecimento de experiências concretas no exterior sobre o uso da interculturalidade sociocultural e linguística em contextos concretos. Aqui foi considerada a importância da realização de pesquisas no Núcleo Takinahaky de Ensino Superior de Professores Indígenas, pertencentes à Universidade Federal de Goiás. Este é um projeto acadêmico aprovado em 28 de julho de 2006, por professores universitários, professores indígenas da Universidade Federal de Goiás (UFG) com o apoio da Universidade Federal do Tocantins (UFT) e da Fundação Nacional do Índio (FUNAI).

A primeira geração foi instituída no ano de 2007 e contou com a participação de alunos dos seguintes povos indígenas: Apinajé, Canela-Apanyekrá, Canela Ramkokamekrá, Gavião, Guajajara, Javaé, Karajá, Krahô, Krikati, Tapirapé, Tapuio e Xerente. Eles se somam a outros como Xasmbioá, Guarani, Timbira, Guajajara, Xavante, Kamaiura, entre outros que desde 2017, compõe 22 grupos étnicos da região. Na sequência são apresentadas atividades que foram realizadas pelos estudantes indígenas de Oaxaca, já na instituição:

1. Apresentação do programa, seu sentido pedagógico e as expectativas dos estudantes indígenas, seus diretores e acadêmicos encarregados de supervisionar esta atividade.

2. Os alunos indígenas que participaram do evento foram distribuídos nas diferentes salas de aula para receber aulas e interagir com os professores indígenas em formação. 
No final de cada dia e semana, foram realizadas sessões de intercâmbio, que também serviram para refletir, bem como para complementar as conclusões de cada encerramento de atividade.

3. Nos finais de semana, no contexto das atividades de avaliação e apresentação de resultados, os alunos indígenas do Brasil e do México fizeram suas apresentações acadêmicas e culturais, que foram focadas em vários objetos de estudo (línguas indígenas, recuperação de práticas cultural, gestão de práticas didáticas entre outros.) Atividades como amostras de progresso acadêmico foram planejadas em conjunto, para alertar o trabalho de ambos os países. Aqui os mesmos estudantes e pesquisadores da instituição poderiam participar como públicos.

4. Também nos fins de semana eles realizaram sessões de intercâmbio de atividades culturais dos dois países. (Foi significativo aqui como os dois grupos usam a tecnologia para mostrar suas práticas culturais o mais próximo possível de sua realidade, atividades de dança e canções populares também foram apresentadas).

5. Da mesma forma, outras atividades foram realizadas para apresentar os avanços das pesquisas como mostras culturais por meio da dança e uma oficina sobre alebrijes, nas dependências do museu antropológico da Universidade Federal de Goiás.

\section{Documentação narrativa das experiências dos alunos no Programa de Internacionalização}

Para explorar em profundidade as ideias que os professores indígenas apoiam sobre a experiência de mobilidade no exterior e buscar o potencial de mudança em outros cenários, pretendeu-se acompanhar a experiência recuperando vários dos princípios de pesquisa-ação participativa propostos por Anderson (2007) e Podestá (2007). Também foi decidido reunir informações ao pedir aos alunos que fizessem uma narrativa da experiência vivida de maneira detalhada de tudo o que significava para eles a experiência (SUÁREZ, 2006). Eles também foram solicitados a fazer uma troca de histórias entre eles, de tal forma que um outro registro pudesse ser usado como base para documentar a experiência com mais detalhes.

A utilização das narrativas dos alunos como estratégia para recuperar informações da experiência foi muito importante pois permitiu a prestação de contas por meio de seus discursos, avaliando se os objetivos da experiência foram cumpridos e, sobretudo, foi uma maneira de acessar as crenças e opiniões de professores indígenas. 
A análise de suas histórias possibilitou a identificação de várias categorias de interpretação, como as seguintes, que foram agrupadas em cinco grandes blocos: 1) informações gerais sobre como a experiência foi preparada para vivenciá-la; 2) informações relacionadas à assiduidade nas aulas; 3) informações sobre aspectos relacionados a experiências extraclasse; 4) Informações referentes ao material e recursos utilizados para realizar suas apresentações acadêmicas e culturais; 5) informações que permitem obter dados referentes à forma como concretizaram a experiência vivida.

Para a seleção dos depoimentos, os considerados mais relevantes, foi feita com base na experiência acadêmica vivida.

\section{Experiências relatadas relacionadas aos vínculos interculturais entre o Brasil e o México}

O propósito de apresentar esses depoimentos é mostrar, com alguns exemplos, como os estudantes vivenciaram a experiência de internacionalização. Embora os entusiasmos possam ser percebidos na experiência vivida, observa-se também a persistência em apresentar grandes contribuições acadêmicas que contribuíram para a prática acadêmica realizada. Outro aspecto, que também é significativo, está relacionado ao progresso alcançado de maneira concreta nas pesquisas. Por fim, vale ressaltar que consideramos a importância de divulgar e compartilhar os relatos de experiência, bem como a interpretação dos mesmos que foram apresentados neste estudo, para que outros cursos de Pós-graduação em Educação aproveitem ou possibilitem experiências acadêmicas, como a atual, de caráter internacional.

\section{i) Preparação para a experiência. O compromisso social dos povos indígenas.}

Nesta seção destacam-se os aspectos do compromisso social dos estudantes com seus povos, compromisso que vai além da conclusão de estudos de pós-graduação de natureza acadêmica, pois enumeram-se outros relacionados à consciência de suas responsabilidades familiares mas, acima de tudo, o de que estudar significa ter obrigações sociais, pensando que a preparação vai além de ter uma ascensão social de caráter individualista. Estudar, para eles, significa pensar sobre o outro, em sua comunidade, no país. Também é importante notar que os cursos frequentados e os conteúdos estudados tiveram como foco a utilização em situações de suas realidades (aprender a documentar suas práticas socioculturais e linguísticas, a melhoria do ambiente, contação de histórias para os alunos e a criação de uma biblioteca em sala de aula) 
bem como a implicação pedagógica e didática desse conhecimento. Como fragmentos, dos relatos de experiência de alguns alunos, são destacados os seguintes:

Em todos esses anos, neste importante trabalho em frente aos alunos do ensino fundamental, percebo que meus objetivos iniciais são muito importantes e que muito é necessário para trabalhar. Então, quando recebi o convite para entrar no mestrado em Pedagogia na UNAM, eu fiquei muito alegre e ainda me assusto porque eu senti que é um grande desafio para mim porque eu tenho família, meu marido e dois filhos, e isso é muito grande para mim historicamente e culturalmente pois são grandes compromissos sociais. (Depoimento de estudante)

Mas o que me faz sentir segura e me incentiva é o meu objetivo para ajudar a melhorar a educação, não só na minha comunidade, mas no meu país e em outras áreas, principalmente ajudar nossos irmãos das comunidades, para que sejamos valorizados e nos tornemos visíveis. Confesso que eu ainda me sinto aterrorizada, porque assumirei grandes responsabilidades. (Depoimento de estudante)

Aprendi que, para documentar a experiência, as práticas educacionais e o conhecimento tradicional de nossas comunidades indígenas, é preciso, antes de mais nada, saber onde realizar a pesquisa ou as pesquisas, a quem elas ajudarão a documentar, quando devem documentar? No momento em que o evento ou ritual está acontecendo, organize-se para a coleta de dados, por meio de entrevistas. Para que esse conhecimento será documentado? Porque e qual a importância de documentar? Como documentar a pesquisa ou as pesquisas? Através da entrevista com os idosos por meio de fotos, vídeos, antologias escritas, livros, espaços onde posso realizar a pesquisa, campo, escola e locais sagrados, com temas de nosso interesse, começando pela definição. (Depoimento de estudante)

\section{ii) Experiência na riqueza de conhecimentos, sentimentos, valores e ações}

Na investigação das histórias, observa-se que os alunos indígenas destacaram muito suas experiências entre os diferentes cursos em que participaram. Acima de tudo, destacaram o entusiasmo por estarem presente neste tipo de experiência, por conhecerem outras pessoas, outros estilos de aprendizagem e de ensino. Vários depoimentos também permitiram obter informações sobre a avaliação dos professores em relação aos conhecimentos culturais e, acima de tudo, sobre a importância de defender seus direitos humanos e culturais. Nesta ocasião puderam assistir a vários cursos entre os quais se destacam Direitos dos povos indígenas, Documentação dos saberes tradicionais em línguas indígenas, entre outros.

Esta parte me identificou ainda mais e reforça minha coragem de continuar me preparando para fazer a minha parte para evitar essa situação, como estão fazendo os companheiros do Centro de Educação Intercultural Takinahaki, um exemplo a seguir. A aula sobre Direitos do Conhecimentos Tradicionais, com a professora Dra. Luciana Oliveira, foi importante porque 
eu não sabia muito sobre direitos internacionais e que até do Brasil eu conheci. (Depoimento de estudante)

Reunimos ideias e sentimentos em sala de aula, o que me fez refletir que muitos de nós sofrem injustiças e que devemos nos unir em diferentes espaços e que nossa contribuição para melhorar a educação na América Latina é um grão de areia. (Depoimento de estudante)

Atenção ao curso de "meio ambiente e transformação", ao entrar na aula estava lidando com a origem do mundo a partir da conceituação das culturas originais, lá me lembrei de alguns cursos realizados e histórias sobre o assunto e também refleti sobre tantos aspectos que não tive a curiosidade de entrar em minha cultura e saber como a partir do Zapoteca é concebida a criação do mundo, permanecendo assim uma tarefa pendente. (Depoimento de estudante)

\section{iii) As experiências interculturais}

As conversas informais entre eles destacaram a troca de conhecimentos sobre tradições rituais, ofícios, material bibliográfico, entre outros. Houve também opiniões sobre o tipo de alimentação, a atitude hospitaleira de seus pares e a atitude receptiva de seus pesquisadores, uma vez que estes foram considerados elementos importantes para o conhecimento sobre a cultura brasileira. Também era altamente valorizado poder viver diariamente muitas danças e rituais que seus colegas frequentemente lhes ensinavam.

Tivemos a oportunidade de compartilhar e trocar conversas com nossos colegas durante nossas horas de recesso, algumas muito interessantes com um dos mestres Xavantes com mais antiguidade, ele nos contou sobre os cavalheiros que se transformaram em relâmpagos, que eu pensei que coincide com os nahuales que também existem nas comunidades de Oaxaca. Outros aspectos muito interessantes foram relacionados aos dicionários que eles têm em suas línguas nativas e ainda mais quando um dos colegas me deu o dele. Para mim foi algo muito especial. (Depoimento de estudante)

Essa experiência foi muito enriquecedora, e os professores nos levaram para um restaurante onde pudemos saborear outras deliciosas comidas do Brasil, que pareciam muito familiares pelo aspecto do lugar, e pudemos conhecer um pouco mais os professores. (Depoimento de estudante)

Naquele dia, voltamos ao auditório para ouvir as exposições dos companheiros das diferentes culturas e, de uma maneira pessoal, me senti muito feliz porque me convidaram a participar de seus rituais que expressavam algumas das culturas presentes. (Depoimento de estudante)

\section{iv) Experiência em apresentações acadêmicas}

As apresentações acadêmicas sobre o progresso das pesquisas dos estudantes do Núcleo Takinahaky de Educação Superior de Professores Indígenas é uma prática que se realiza rotineiramente aos sábados, que é quando se pretende ter conhecimento de como estão 
progredindo as pesquisas dos estudantes sobre: seus achados teóricos ou evidências empíricas; como eles recuperaram a colaboração familiar e o conhecimento dos sábios de suas comunidades; como eles organizam os conteúdos de um modo situacional; como eles elaboram suas exposições para tornar público o progresso de seu trabalho, entre outros aspectos.

Nesse contexto, os alunos indígenas do programa de pós-graduação em Pedagogia da FES Aragón também deram a conhecer seus avanços acadêmicos, relataram o que têm trabalhado como equipe de pesquisa e também seus achados individuais. A equipe comentou que contribuiu muito a experiência, uma vez que ela permitiu continuar a melhorar as habilidades acadêmicas para o trabalho intelectual. Nesse momento, feitas as apresentações, observou-se que o trabalho realizado pelo chamado tequio acadêmico e com a ABP foram bem valorizados no sentido de alcançarem maior profundidade acadêmica.

Foi uma experiência muito satisfatória, pois, para apresentar meu projeto naquele espaço, consegui ordenar um pouco mais minhas ideias e adquiri um pouco mais de segurança. Também pude mostrar parte da minha cultura como um zapoteco e como um Oaxaca, eu me senti muito feliz, ainda mais porque os companheiros viveram conosco. (Depoimento de estudante)

Em relação à apresentação do meu trabalho, posso dizer que tentei me explicar de forma breve e me preocupei em expressar a importância da minha pesquisa, devido à linguagem, me ajudou a entender melhor meus objetivos. Além disso, a ideia de contribuir para os alunos em formação me deixa muito empolgada porque acredito que o caminho da incerteza que começou há alguns meses começa a clarear pouco a pouco. (Depoimento de estudante)

Aprendi que o trabalho coletivo nos ajuda a alcançar maiores conquistas, como uma equipe que fomos ao Brasil. Nos apoiamos muito desde a compra dos boletos de viagem, a transferência para a Cidade do México, as companheiras que nos receberam em sua casa, o acompanhamento físico dos professores, suas recomendações o tempo todo. (Depoimento de estudante)

\section{v) Experiências em apresentações acadêmicas em equipe}

Lidar com a pesquisa acadêmica e sua escrita com os alunos novatos têm maneiras diferentes: os professores das universidades parecem preferir trabalho individual em diferentes tipos de pesquisa, embora o trabalho em equipe seja valorizado positivamente.

É possível que, na tentativa de incentivar o tequio acadêmico baseado em $\mathrm{ABP}$, não estejam presentes para a formação de estudantes indígenas diferentes formas de agrupamento dos alunos durante todo o processo de formação de pesquisadores, mas consideramos que uma prática acadêmica é necessária para dar uma visão complexa desse processo. Enquanto se está incentivando o desenvolvimento da pesquisa individualmente em universidades, e, portanto, 
requer uma atenção específica a cada aluno, incentivando formação profissional como proposto aqui, não é mais uma forma de conhecimento cultural e social que permite a participação em atividades de natureza muito diversa, como também indicou Wenger (2010).

Como pode ser visto nos testemunhos que foram melhor valorizadas suas apresentações que eram provenientes de um trabalho acadêmico em equipe e também o fato de suas pesquisas no contexto terem maior profundidade acadêmica e um sentido social para eles:

Durante a viagem eles nos disseram que a participação tinha sido muito importante, enfatizando principalmente o trabalho em equipe, acho que nesse sentido o objetivo foi alcançado. (Depoimento de estudante)

Também como parte das atividades que realizamos no núcleo foi a apresentação de nossos projetos coletivos $e$ individuais $e$ a Guelaguetza digital. Os participantes estavam interessados em que nossos projetos individuais partissem de um trabalho coletivo e de lá os indivíduos saíssem. Eles nos disseram que acharam essa forma de trabalho interessante porque sempre fazem trabalho individual e não coletivamente. (Depoimento de estudante)

Ao fazer essa atividade, comecei a refletir sobre tudo o que podemos fazer, mas muitas vezes não percebemos o potencial que trazemos para dentro de nós e duvidamos do que podemos fazer e é difícil acreditar nisso. (Depoimento de estudante)

\section{vi) Experiências de intercâmbios culturais}

A promoção do estudo e o fortalecimento de práticas culturais em programas de pósgraduação para estudantes indígenas é um aspecto ao qual os acadêmicos atribuem grande importância. Esta atividade de troca de experiências culturais foi muito importante e valorizada pelos alunos do Mestrado em Educação e pelos professores e alunos do Centro que observaram a importância deste aspecto (costumes, trajes, organização, música, oficina, etc.).

Essa experiência de intercâmbio acadêmico permitiu que eles compreendessem melhor as estruturas culturais internas que possuem, o que favorece um entendimento diferente e melhor das descobertas acadêmicas que os alunos vêm construindo. $\mathrm{O}$ trabalho de intercâmbio compartilhado favorece o desenvolvimento de uma identidade, já que se tornam mais ricos os conhecimentos acadêmicos que adquiriram e mais complexa e extensa visão de conhecimento cultural porque agora conhecem melhor a si mesmos e sabem da existência de outras práticas culturais (BARRÓN, 2006). 
Este curso também nos permitiu compartilhar nosso trabalho com nossos colegas e mostrar-lhes um ritual como os realizados em Oaxaca, que os surpreendeu porque são um pouco diferentes dos deles. Eles também exibiram seus rituais e, no meu caso, permitiram que eu soubesse mais sobre suas culturas e entendesse por que muitos pesquisadores estão interessados em suas práticas culturais que, do meu ponto de vista, ainda preservam características próprias, que foram descontinuadas nos rituais do nosso povo em Oaxaca. (Depoimento de estudante)

Nós compartilhamos um documentário de uma experiência de documentação que foi realizada pelos jovens da escola secundária comunitária de Solaga, novamente lembrando da minha comunidade. Um vídeo de uma experiência pedagógica também foi compartilhado em San Mateo del Mar, ambos editados pela UNICEF e pela CIESAS. Essa partilha com os colegas parecia reforçar a comunicação, eles estavam interessados em querer saber mais sobre nós, os costumes do México, por exemplo, sobre a festa dos mortos, o que a morte representa para nós, entre outras coisas. (Depoimento de estudante)

Após a exposição, a Dra. Rosani [Moreira Leitão] nos convidou para participar da semana seguinte, no Museu de Antropologia, onde também fizemos a mesma apresentação. Ela incluiu a oficina de escultura em madeira, que havíamos planejado, foi também uma experiência muito agradável e enriquecedora. (Depoimento de estudante)

\section{vii) Descobertas da experiência global}

Se levarmos em conta a grande importância que os estudantes indígenas de Oaxaca dão à experiência de internacionalização, faria muito sentido o valor que eles dão aos achados de suas pesquisas em equipe e de pesquisadores em formação, já que as informações agora adquiridas a partir da vivência de seus objetos de estudo, em outros contextos, permitiram que eles tenham maior segurança na medida em que lideram como pesquisadores (GIMENO, 2012). Portanto, parece aconselhável caminhar em conjunto com estudantes e pesquisadores acadêmicos nesse processo de formação tão complexo e ao mesmo tempo enriquecedor.

Posso dizer que, nessa experiência pedagógica e formativa em nível pessoal e profissional, aprendi, soube, desaprendi e reafirmei muitos aprendizados. Sou grato por conhecer pessoas tão valiosas quanto os professores doutores de Educação Intercultural do Núcleo Takinahaky de Educação Superior de Professores Indígenas. Foram eles que me deram um exemplo de simplicidade, entusiasmo, tomada de decisão e como pensar sobre a vida de uma maneira integral. (Depoimento de estudante)

Mais tarde, tivemos a oportunidade de trabalhar como assistentes de professores doutores, que nos mostraram alguns vídeos de jogos e sua importância no cotidiano para depois sairmos e compartilharmos com nossos colegas um jogo da nossa cidade. Durante essa atividade, fiquei impressionado com o fato de que os professores cantaram e executaram danças que fazem parte de seus rituais, mas não apresentaram nenhum tipo 
de brincadeira. Nesse sentido, houve outro professor de apoio, que nos ensinou um jogo que me motivou a participar, mostrando dois jogos de trabalho em equipe. Os professores expressaram tanto prazer que pediram para repetir o jogo. Todos voltamos sorrindo e animados para as atividades em classe, conversamos e trocamos nossos endereços eletrônicos para compartilhar no Facebook e nos comunicarmos posteriormente. (Depoimento de estudante)

Saímos para tomar uma caipirinha e dançar samba e forró no último dia da minha estadia em Goiânia, também foi uma ótima experiência. Nós éramos mais de 10 e todos nós compartilhamos um tempo bom depois de uma semana longa de atividades. Dançamos, comemos e bebemos e essa é a última imagem que tenho em minha mente de um grupo que um dia decidiu viajar para o Brasil a convite de uma professora que no primeiro dia de aula nos deu uma caixa com um real (a moeda brasileira) dentro dela, dizendo algo como: nesta caixa, eles guardarão todas as moedas dos diferentes países que visitarão durante seus estudos de pós-graduação. Até este momento, parece-me uma bela previsão. (Depoimento de estudante)

\section{Conclusões}

Vínculos binacionais favorecem a geração e a aplicação do conhecimento dos estudantes que irão expandir e revitalizar, com o apoio teórico sobre os resultados de investigações específicas, os ideais de recuperação e consolidação dos seus conhecimentos e saberes ancestrais.

Com a conclusão deste trabalho acadêmico, temos uma visão geral sobre os alunos indígenas como equipe de pesquisa numa experiência de internacionalização com base em duas perguntas: quando e como começar no contexto do currículo este tipo de experiência e quanto a promoção de experiências de internacionalização para estudantes de pós-graduação indígenas é uma questão importante para universidades ou instituições de ensino superior?

Os depoimentos desta pesquisa indicam a importância de dedicar tempo e empenho dentro do horário escolar acadêmico para viajar ao exterior buscando estabelecer parcerias para que os alunos aprendem a ter uma experiência como essa, porque lhes permite crescer como indivíduos e também melhorar a qualidade dos seus trabalhos de pesquisa.

Este texto procura mostrar a necessidade de que os professores de pós-graduação que atuam em comunidades indígenas, mudem sua forma tradicional de fomentar a formação de pesquisadores e estejam mais articulados à dinâmica de nossos tempos. Estamos convencidos de que a maioria deles gosta da promoção da pesquisa como prática individual e que as instituições educacionais frequentemente reforçam essa tarefa. No entanto, nesta experiência, estamos comprometidos com a possibilidade de que exista, nas comunidades, oportunidade de 
recuperar um sentido de trabalho colaborativo denominado tequio acadêmico baseado em $\mathrm{ABP}$ como recurso que pode redirecionar o trabalho intelectual que vem articulado à formação de estudantes.

É possível pensar que a promoção do trabalho colaborativo é uma atividade acadêmica muito necessária para dar uma visão complexa desse processo. Enquanto a produção de conhecimento é possível ocorrer individualmente e, portanto, requer uma atenção específica a cada aluno, o conhecimento colaborativo não deixa de ser uma forma de conhecimento cultural e social que permite a participação em atividades de diversas naturezas acadêmicas como também notou Wenger (2010) com suas comunidades de prática. O trabalho colaborativo dentro desse grupo de estudantes indígenas é um aspecto ao qual damos grande importância. Esta atividade de trabalho colaborativo tem nos mostrado uma variedade de autores (OLMOS; CARRILLO, 2009), o que indica sua relevância para favorecer o desenvolvimento social e mais ainda por também permitir uma mudança interna na cultura acadêmica.

O trabalho colaborativo permite que os alunos compreendam as estruturas internas da essência cultural que possuem, o que favorecerá a compreensão de diferentes problemas sociais vivenciados em seu contexto.

Da mesma forma, o tequio acadêmico como uma atividade compartilhada favorece a transformação de contextos, uma vez que o torna mais rico, complexo e extenso, um aspecto que tem sido diretamente relacionado a um ótimo desenvolvimento do trabalho intelectual. Considerando a grande importância que as comunidades indígenas destinam ao trabalho colaborativo, faria muito sentido o valor que os professores dão à colaboração com as famílias também reverberasse em espaços educacionais pois estes dois tipos de ação são muito importantes e necessários para as trocas comunicativas que ocorrem com frequência nos contextos escolares. Em última análise, a escola é responsável pelo processo de colaboração e, por isso, nos parece muito aconselhável caminhar com os estudantes indígenas em um processo formativo, de protagonismo e tão complexo.

\section{REFERÊCIAS}

ANDERSON, G. Hacia una participación auténtica: Reconstruyendo los discursos de las reformas participativas en educación. In: Narodowski, M. y otros (Coords), Nuevas tendencias en políticas educativas, Buenos Aires: Temas/ Fundación Gobierno y Sociedad, 2002. 
ARAUJO, U.; SASTRE, G. EI aprendizaje basado en problemas: una nueva perspectiva de la enseñanza en la universidad. Barcelona: Gedisa, 2008.

BARRÓN, C. Proyectos educativos innovadores. Construcción y debate (compilación). México: CESU/UNAM, 2006.

CASTAÑEDA, J. A. S. Alrededor de la idea de formación. In: C Salinas (coord.), La investigación educativa en México. México. V Congreso Nacional Educativa. COMIEUPN, 2001.

DIDRIKSSON, A. La universidad de la innovación. México. CESU/UNAM, 2015.

GIMENO, J. S. Educar y convivir en la cultura global. Madrid: Morata, 2012.

HARGREAVES, A. Profesorado, cultura y postmodernidad (cambian los tiempos, cambian los profesores). Madrid: Morata, 1995.

LASALA, M. Desde la escuela tradicional hacia la interculturalidad: una experiencia de construcción del aprendizaje”. Revista Novedades Educativas. No. 233, 2010.

MALONE, H. J. (COOR). El rumbo de la transformación educativa: temas, retos globales y lecciones sobre la reforma estructural. México: FCE, 2016.

OLMOS, A.; CARRILLO, A. Juego y Alfabetización: bases para un sistema educativo cultural vygotskiano. México, UNAM- Miguel Ángel Porrúa, 2009.

PALLAN, C. F et al. El intercambio académico internacional en México. Temas de hoy en la educación superior, N. 12, México. ANUIES, 1996.

PODESTÁ SIRI ROSSANA. En metodologías participativas nuevos retos y roles intelectuales. RMIE, 12 (34), pp. 987-1014, 2007.

REIMERS F.; CHUNG, M. Estudios comparativos de los propósitos de la educación en el siglo XIX, México: F.C.E, 2016.

RODRÍGUEZ-MENA, M. Aprender en Comunidades de Práctica. Presupuestos teóricos y metodológicos para potenciar el aprendizaje en espacios sociales. La Habana: CIPS, 2011.

SHIRLEY, D. "Enseñanza inteligente con tecnología: pasos hacia la armonización”. In: MALONE H. (Coord). El rumbo de la transformación educativa: temas, retos globales y lecciones sobre la reforma estructural. México: FCE, 2016.

STOLI, L. Capacidad de aprendizaje. Tomar en serio la mejora de la docencia. In: MALONE, $\mathrm{H}$. (Coord). El rumbo de la transformación educativa: temas, retos globales y lecciones sobre la reforma estructural. México: FCE, 2016.

SUÁREZ, D. Documentación narrativa de experiencias pedagógicas. Una manera de indagar el mundo y la experiencia escolares. Revista Entre Maestr@s, 5, (16), pp. 11-25, 2006. 
SUÁREZ, D. Los movimientos político-pedagógicos latinoamericanos y la reconstrucción crítica del saber pedagógico: el "horizonte de posibilidad" en América Latina. Clase 8 del curso virtual "Historia y Prospectiva Crítica del Pensamiento Pedagógico Latinoamericano". Espacio de Formación Virtual de la Red CLACSO de Posgrados en Ciencias Sociales. Cátedra Florestan Fernandes, 2010.

SUÁREZ, D.; HILllerT, F.; OUVIÑA H.; RIGAL L. Pedagogías Críticas en América Latina: Experiencias Alternativas de Educación Popular. Buenos Aires, Noveduc, 2016.

VYGOTSKI, L. S. EI desarrollo de los procesos psicológicos superiores. Barcelona, Crítica, 1978.

VYGOTSKI, L. S. Psicología del arte. Barcelona Barral, 1982.

WENGER, E. Comunidades de práctica: aprendizaje significativo e identidad. Barcelona: Paidós, 2010.

ZAMBRANA, A. "La universidad frente a la diversidad y al Estado plurinacional de Bolivia”. In: Zambrana, A. (edit.). Pluralismo epistemológico: reflexiones sobre la educación superior en el Estado plurinacional de Bolivia. FUNPROEIB Andes, Cochabanba. pp.185-205, 2014.

\section{Como citar este artigo:}

AVELAR, Antonio Carrillo; ROA, Andrea Olmos; CUSATI, Iracema Campos. Articulações entre educação intercultural e práticas de internacionalização entre México e Brasil. Revista Ibero-Americana de Estudos em Educação, Araraquara, v. 14, n. 3, p. 1182-1204, jul./set., 2019. e-ISSN: 1982-5587. DOI: 10.21723/riaee.v14i3.12486

Data de Submissão: 10/01/2019

Revisões requeridas: $25 / 02 / 2019$

Aceite em: 27/03/2019

Publicado em: 11/05/2019 